\title{
The effect of physiotherapy on the mobility of patients with cognitive impairment
}

\author{
Kristina Batič, Marjetka Gomboc \\ University Psychiatric Clinic Ljubljana, Ljubljana, Slovenia \\ kristina.batic@psih-klinika.si; marjeta.gomboc@gmail.com
}

\begin{abstract}
Introduction: Good mobility is crucial for achieving a good quality of life among the elderly. Factors that affect mobility include aging, disease, and injury, but also cognitive decline. A common reason for admitting an elderly person to hospital care are complications associated with the factors mentioned above. Being admitted to the hospital causes additional stress among the elderly, which in practice manifests itself as a risk factor for reduced mobility during hospitalization. The aim of the present study was to determine the effect of a 14-day physical therapy aiming at maintaining or improving the patient's mobility. Methods: We used a quantitative retrospective design. The study included 36 patients, 25 of whom were women ( $73.5 \%)$ and 9 were men $(26.5 \%)$. They were divided into 3 groups, based on the number of points each individual achieved in the Mini-Mental State Examination test (MMSE). They were grouped according to the guidelines of validated Slovenian version of MMSE as follows: 23-19 points - mild cognitive impairment (17 patients), $18-11$ points - moderate cognitive impairment (12 patients) and 10 points or less - severe cognitive impairment ( 5 patients). Patients included in the study were admitted to the Gerontopsychiatric Unit of the University Psychiatric Clinic Ljubljana between October 2020 and April 2021. Inclusion criteria were: aged 60 years or older, confirmed cognitive decline with MMSE, and inclusion in the physical therapy. Exclusion criteria included: worsening of chronic disease, acute deterioration of health or a fall during hospitalization. To assess the patient's mobility, we used the de Morton Mobility Index (DEMMI). Due to the abnormal distribution of the analysed data, the Wilcoxon signed-rank test was used to examine the differences between the first and second assessment with the DEMMI test. The statistical significance of $\mathrm{p}<0.05$ was taken into account. Results: In the second assessment, the results of the DEMMI test in all three groups improved. The most visible
\end{abstract}


improvement is observed in the group with a moderate cognitive decline (18 $\leq$ MMSE $\leq 11$ points), which is statistically significant $(\mathrm{p}=0.005)$. A statistically significant improvement was also observed in the group with mild cognitive impairment ( $19 \leq \mathrm{MMSE} \leq 23$ points $)(\mathrm{p}=0.005)$. The improvement in the second assessment with the DEMMI test, which is evident in the group with severe cognitive impairment, is not statistically significant $(\mathrm{p}=0.109)$. Discussion and conclusions: Existing research shows the importance of adequate physiotherapy treatment of people with cognitive impairment. Our research has also shown that targeted physical therapy preserves or even improves the mobility of people with cognitive impairment, regardless of the degree of the latter.

Keywords: cognitive impairment, mobility, physiotherapy

\section{Introduction}

The world's population is ageing. In 2020, there were 727 million people aged 65 and above. Over the next 30 years, the world's population aged 65 and above is expected to more than double and reach more than 1.5 billion by 2050 (UN, 2020). At the same time, there is also an increasing number of people suffering from dementia. In 2020, there were 50 million people worldwide with dementia. By 2050, that number is expected to rise to 152 million (Alzheimer's disease International, 2020). Due to the ageing of the world's population, the World Health Organization (WHO, 2021) emphasises the importance of improving the lives of older adults and healthy aging. According to the WHO (2020), healthy aging is »the process of improving or maintaining functional abilities that enable wellbeing in older age « (WHO, 2020). Functional abilities include mobility. Mobility is an umbrella term for changing and maintaining body position (e.g. lying down, sitting, getting up) or moving in a position (e.g. moving in a lying position from one side to the other) or from one place to another. It also involves moving to different locations (e.g., at home) or moving using different means of transportation (MKF, 2006).

In the elderly, the key factor for maintaining a good quality of life is preserving good mobility (Le Grow et al., 2013). However, ageing is often associated with reduced mobility and decreased functional (Mahmood Khan, 2017) and cognitive abilities (Murman, 2015). These changes are closely related. Recent researchers (Pedersen et al., 2014; de Melo Borges et al., 2015) argue that the elderly with mild cognitive impairment show more mobility limitations compared to the elderly with intact cognition. In addition to the decline in cognitive abilities, the factors influencing mobility in the elderly are reduced physical activity, obesity, decreased muscle strength, balance disorders and various chronic diseases (Brown et Flood, 2013). The predominant chronic diseases associated with reduced mobility in older adults include hypertension, osteoarthritis, cardiovascular disease, cancer, respiratory disease, diabetes, and stroke (Manini, 2011). Moreover, the occurrence of sarcopenia in old age and the associated decrease in muscle mass and muscle strength also causes problems with 
balance and walking (Marques et Queiros, 2018), which can lead to mobility limitations (Cruz-Jentoft et al., 2019) and to a higher incidence of falls (Yeung et al., 2019). These problems often lead to hospitalisation of older adults, which is an additional risk factor for reduced mobility in the elderly (Surkan et Gibson, 2018) especially in people with cognitive decline (Hartley et al, 2017).

In addition to cognitive decline, reduced mobility is one of the main risk factors for falls among the elderly (Terrosso et al., 2014). The risk of falling is almost three times higher in older adults with moderate to severely reduced mobility compared to those without any restraints (Musich et al., 2018), while in older adults with dementia, the risk of falling is two times higher than in the elderly with intact cognition (Allali et al., 2017). Both reduced mobility and cognitive decline lead to a decrease in an individual's independence in performing activities of daily living (ADLs) (Heiland et al. 2016; Mograbi et al., 2017) and increase mortality (Frith et al., 2015; Bergland et al., 2017).

Previous research shows a positive effect of exercise on cognitive abilities, maintaining mobility and independence in performing ADLs in people with dementia (Liu et al., 2020). Furthermore, therapeutic exercise improves strength, balance, walking, and endurance in people with mild cognitive impairment (Lam et al., 2018), which shows the relevance of including people with cognitive impairment in physiotherapy treatment. In addition, a higher frequency of physiotherapy treatments during hospitalisation shortens the length of stay, improves functional status and increases independence with ADLs upon discharge (Hartley et al., 2016).

However, the effect of physiotherapy treatment on people with cognitive impairment remains insufficiently researched. The aim of our research is to investigate the effect of a 14-day physiotherapy treatment on the mobility of hospitalised patients with cognitive decline.

\section{Methods}

A retrospective quantitative pilot research was conducted. The research included patients admitted to Gerontopsychiatric Unit of the University Psychiatric Clinic Ljubljana between October 2020 and April 2021. Inclusion criteria were age 60 and above, cognitive decline confirmed by Mini Mental State Exam (MMSE) and inclusion to physiotherapy treatment. The exclusion criteria were exacerbation of a chronic disease and acute health deterioration.

The De Morton Mobility Index (DEMMI) was used to assess mobility. It is a standardised measuring instrument used to assess 15 items, including mobility in bed, mobility on a chair, static balance, dynamic balance and walking. Eleven items were evaluated with a 2-point scale, and the remaining four with a 3-point scale. The maximum that an individual could have achieved is 19 raw points that were converted into interval-level DEMMI points. Minimum of o points means complete dependence while 100 points means complete independence in mobility (de Morton et al., 2008). Braun et al. (2018) confirmed 
that the DEMMI test has satisfactory psychometric characteristics for assessing older adults with cognitive decline.

The Slovenian version of the Mini-Mental State Exam (MMSE) was used to assess cognitive function. A 30-point questionnaire assessed orientation, attention, memory, language and visual-spatial skills. According to the score obtained, the patients were divided in three groups: intact cognition $(20-24$ points), mild cognitive impairment ( 23 - 19 points), moderate cognitive impairment (18 - 11 points) and severe cognitive impairment (10 points or less) (Granda et al., 2003).

Physiotherapy treatment was customised according to individual's needs and abilities. It included individual exercises, strength exercises, and exercises to improve static and dynamic balance and coordination, transfer training and walking training. Tests and physiotherapy treatment were performed on the premises of the Gerontopsychiatric Unit of the University Psychiatric Clinic Ljubljana. For each patient, mobility was assessed twice; firstly before enrolment in physiotherapy treatment and secondly after 14 days of physiotherapy treatment.

The anonymised data used in the study was obtained from physiotherapy treatment records. The Commission for Ethical Issues at the University Psychiatric Clinic Ljubljana approved the use of data on the $24^{\text {th }}$ of May 2021. The protection of personal data has been ensured. It was used for research and publishing purposes only.

The data was edited in Microsoft Office Excel 2016 (Microsoft Corporation, New York, USA) and exported for statistical analysis to IBM SPSS Statistics for Windows 25.0 (IBM Corporation, Armonk, New York, USA). Descriptive statistics were given as count (with percentage) or mean (with standard deviation). Shapiro-Wilk test showed the data distribution of the first ( $\mathrm{p}=$ o.018) and second ( $\mathrm{p}=0.026)$ DEMMI test was abnormal. To determine the differences between the first and second DEMMI test the Wilcoxon test was used. Statistical significance was set at p-value $<0.05$.

\section{Results}

In the period between October 2020 and April 2021, 146 patients were tested twice. More precisely, 55 patients $(38 \%)$ were enrolled to physiotherapy treatment.1 patient ( $2 \%$ ) was younger than 60,16 patients $(29 \%)$ did not conclude MMSE or MMSE did not confirm cognitive decline, 4 patients (7\%) experienced exacerbation of chronic disease or acute health deterioration. The remaining 34 patients (62\%) were divided into three groups according to the degree of cognitive impairment: mild cognitive impairment (17 patients, $50 \%$ ), moderate cognitive impairment (12 patients, $35 \%$ ) and severe cognitive impairment (5 patients, $15 \%$ ).

Table 1 shows there were 25 women (73.5 \%) and 9 men $(26.5 \%)$ included in the sample. All three groups had similar representation of women and 
men. The mean age of the patients included in the study was $79.18 \pm 8.67$ years, with patients with severe cognitive decline being the oldest on average $(84,60$ \pm 2.61 ), followed by patients with mild cognitive decline $(79,47 \pm 8.75)$ and patients with moderate cognitive decline (76.50 \pm 9.52$)$.

Table 1: Sample's characteristics

\begin{tabular}{lcccc} 
Group & $\begin{array}{c}\text { Severe } \\
\text { cognitive decline } \\
(N=5)\end{array}$ & $\begin{array}{c}\text { Moderate } \\
\text { cognitive decline } \\
(N=12)\end{array}$ & $\begin{array}{c}\text { Mild } \\
\text { cognitive decline } \\
(N=17)\end{array}$ & $\begin{array}{c}\text { Total } \\
(N=34)\end{array}$ \\
$\begin{array}{l}\text { Age in years } \\
\begin{array}{l}\text { M } \pm \text { SD } \\
(\min -\max )\end{array}\end{array}$ & $\begin{array}{c}84.60 \pm 2.61 \\
(81-88)\end{array}$ & $\begin{array}{c}76.50 \pm 9.52 \\
(60-90)\end{array}$ & $\begin{array}{c}79.47 \pm 8.75 \\
(61-97)\end{array}$ & $\begin{array}{c}79.18 \pm 8.67 \\
(60-97)\end{array}$ \\
\hline $\begin{array}{l}\text { Women N } \\
(\%)\end{array}$ & $3(60 \%)$ & $9(75 \%)$ & $13(76.5 \%)$ & $25(73.5 \%)$ \\
\hline Men N $(\%)$ & $2(40 \%)$ & $3(25 \%)$ & $4(23.5 \%)$ & $9(26.5 \%)$ \\
\hline
\end{tabular}

Legend: $M=$ mean, $S D=$ standard deviation, $N=$ number

The results of the descriptive statistics and the difference between the first and second DEMMI tests in all three groups and Wilcoxon signed-ranked test are shown in Table 2 . In the first assessments, the patients with mild cognitive impairment achieved on average the highest scores (51.47 \pm 22.53 points), followed by the patients with moderate cognitive impairment $(49.50 \pm 19.22$ points). On average, patients with severe cognitive decline (45.80 \pm 23.91 points) achieved the lowest scores in the first assessment.

Table 2: Descriptive statistics of the first and the second DEMMI test and Wilcoxon signed-ranked test

\begin{tabular}{lccc} 
& $\begin{array}{c}\text { DEMMI } \\
\text { Points }(M \pm S D)\end{array}$ & $\begin{array}{c}\text { DEMMI 2 } \\
\text { Points }(M \pm S D)\end{array}$ & p-value \\
\hline Severe cognitive decline & $45.80 \pm 23.91$ & $54.20 \pm 9.37$ & 0.109 \\
\hline $\begin{array}{l}\text { Moderate cognitive de- } \\
\text { cline }\end{array}$ & $49.50 \pm 19.22$ & $63.08 \pm 23.26$ & 0.005 \\
\hline Mild cognitive decline & $51.47 \pm \mathbf{2 2 . 5 3}$ & $65.94 \pm 12.65$ & 0.005 \\
\hline Total & $49.94 \pm 21.03$ & $63.21 \pm 18.09$ & $<0.001$ \\
\hline
\end{tabular}

Legend: $M=$ mean, $S D=$ standard deviation, $D E M M I=$ de Morton Mobility Index

The results of the second DEMMI test improved in all three groups. The greatest improvement was seen in the group with mild cognitive decline. On the other hand, the smallest improvement was observed in the group with severe cognitive decline. The SD of DEMMI test scores in both first and second tests do not exceed $25 \%$ of the $\mathrm{M}$, indicating small differences in mobility within each group.

The results of Wilcoxon signed-ranked test showed statistically significant differences between the results of the first and the second DEMMI test in 
the group with moderate cognitive decline $(\mathrm{p}=0.005)$ and mild cognitive decline $(\mathrm{p}=0.005)$. In addition, a statistically significant difference between the first and the second DEMMI test was shown in the analysis of the whole sample $(\mathrm{p}<\mathrm{o.001})$. In the group with severe cognitive decline, we were unable to confirm a statistically significant difference between the first and the second DEMMI test $(\mathrm{p}=0.109)$.

\section{Discussion}

This research retrospectively examined the effect of physiotherapy treatment on the mobility of older adults with different stages of cognitive decline hospitalised in the Gerontopsychiatric Unit at the University Psychiatric Clinic Ljubljana. In addition, we wanted to determine whether the effect of physiotherapy treatment differs depending on the degree of cognitive decline.

Previous research showed that smaller cognitive impairment is associated with better mobility of an individual (Buchman et al., 2011; Pedersen et al., 2014; De Melo Borges et al., 2015). Our findings confirmed that the highest average score on DEMMI test was achieved by the group with a mild cognitive impairment, followed by the group with a moderate cognitive impairment. The group with a severe cognitive impairment achieved the lowest average score on the DEMMI test. After 14 days of physiotherapy treatment, there was a statistically significant improvement in mobility in the whole sample at the second assessment $(\mathrm{p}<\mathrm{o.001})$. Additionally, the average results of the second DEMMI test were higher in individual groups. The greatest and statistically significant progress in mobility was observed in the group with a mild cognitive impairment $(\mathrm{p}=0.005)$, followed by the group with a moderate cognitive impairment $(\mathrm{p}=0.005)$. The smallest amount of progress, which was not statistically significant, was shown in the group with severe cognitive impairment $(\mathrm{p}=$ o.109). Less progress in more cognitively impaired individuals can be attributed to poorer understanding of instruction (Machiels et al., 2017), poorer performance of complex motor tasks (Wu et al., 2015), and complex ADLs (Perneczky et al., 2006). Furthermore, our findings coincide with those indicated in several research previously conducted, reporting a positive effect of physiotherapy treatment on improving the functional abilities of individuals with cognitive decline (Kovacs et al., 2013; Lam et al., 2018; Gomboc, 2019).

There are important limitations in our research as we included only a small nonrepresentative sample of 34 patients with varying degrees of cognitive impairment. A larger sample would reduce the possibility of random errors in the analysis. In addition, cooperation of a person with cognitive impairment varies daily, which is a challenge in working with people with cognitive decline. In order to better understand the effect of physiotherapy treatment, we suggest further research should be conducted in this field. Prospective research is needed to determine whether the frequency and the duration of physiotherapy treatment plays an important role in mobility outcome. 
Despite limitations of our research, our findings prove positive effect of physiotherapy treatment on the mobility of people with cognitive impairment. Although, the improvement in the group with severe cognitive impairment was not statistically significant, we argue with great certainty that individual physiotherapy treatment customised according to individual's needs and abilities improves an individual's mobility regardless of the degree of cognitive decline.

\section{Conclusions}

Mobility and cognitive decline are closely related phenomena that affect the quality of life of the elderly. The demographic ageing and the increase in the number of elderly people with cognitive difficulties indicate an increasing need to maintain the functional abilities and mobility of these individuals. An additional risk factor to reduce mobility is hospitalisation, which is more common in people with cognitive decline. The inclusion of hospitalised elderly people in physiotherapy treatment has been shown to improve their mobility. Therefore, it is crucial to maintain the mobility and functional abilities of hospitalized individuals with cognitive decline.

\section{References}

ALLALI, G., LAUNAY, C.P., BLUMEN, H.M., CALLISAYA, M.L., DE COCK, A.M., KRESSING, R.W., SRIKANTH, V., STEINMETZ, J.P., VERGHESE, J., BEAUCHET, O. and CONSORTIUM, B., 2017. Falls, Cognitive Impairment, and Gait Performance: Results From the GOOD Initiative. Journal of the American Medical Directors Association, vol. 18, no. 4, pp. $335-340$.

ALZHEIMER'S DISEASE INTERNATIONAL, 2020. Numbers of people with dementia worldwide [online]. [viewed 30 April 2021]. Available from: https://www.alzint.org/u/numbers-people-with-dementia-2017.pdf

BERGLAND, A., JORGENSEN, L., EMAUS, N. and STRAND, B.H., 2017. Mobility as a predictor of all-cause mortality in older men and women: 11.8 year follow-up in the Tromsø study [online]. BMC Health Services Research, vol. 17, no. 22. [viewed 16 May 2021] Available from: https://doi. org/10.1186/s12913-016-1950-O

BRAUN, T., GRUNEBERG, C., THIEL, C. and SCHULZ, R.J., 2018. Measuring mobility in older hospital patients with cognitive impairment using the de Morton Mobility Index [online]. BMC Geriatrics. vol. 18, no. 100. [viewed 20 May 2021] Available from: https://doi.org/10.1186/s12877-018o780-9

BROWN, C.J. and FLOOD, K.L., 2013. Mobility limitation in the older patient: a clinical review. The Journal of the American Medical Association, vol. 310, no. 11, pp. $1168-1177$.

BUCHMAN, A.S., BOYLE, P.A., LEURGANS, S.E., BARNES, L.L. and BENNETT, D.A., 2011. Cognitive function is associated with the development 
of mobility impairments in community-dwelling elders. American Journal of Geriatric Psychiatry, vol. 19, no. 6, pp. $571-580$.

CRUZ-JENTOFT, A.J. and SAYER, A.A., 2019. Sarcopenia [online]. The Lancet, vol. 393, no. 10191, pp. 2636 - 2646. [viewed 15 May 2021] Available from: https://doi.org/10.1016/So140-6736(19)31138-9

DE MELO BORGES, S., RADANOVIC, M. and FORLENZA, O.C., 2015. Functional mobility in a divided attention task in older adults with cognitive impairment. Journal of Motor Behavior, vol. 47, no. 5, pp. $378-385$.

DE MORTON, N.A., DAVIDSON, M. and KEATING, J.L., 2008. The de Morton Mobility Index (DEMMI): An essential health index for an ageing world [online]. Health and Quality of Life Outcomes, vol. 6, no., 63. [viewed 5 May 2021] Available from: https://doi.org/10.1186/1477-7525-6-63

FRITH, E., ADDOH, O., MANN, J.R., WINDHAM, B.G. and LOPRINZI, P.D., 2017. Individual and Combined Associations of Cognitive and Mobility Limitations on Mortality Risk in Older Adults. Mayo Clinic Proceedings, vol. 92, no. 10, pp. $1494-1501$.

GOMBOC, M., 2019. The influence of regular physiotherapy treatment on the functionality of patients admitted to the unit for gerontopsychiatry at the University Psychiatric Clinic Ljubljana. In: ALZHEIMER EUROPE, ed. Making valuable connections: Abstract book / 29th Alzheimer Europe Conference, The Hague, 23 - 25 October 2019. The Hague: Alzheimer Europe, pp. 69.

GRANDA, G., MLAKAR, J. and VODUŠEK, D.B., 2003. Kratek preizkus spoznavnih sposobnosti - umerjanje pri preiskovancih, starih od 55 do 75 let (I). Zdravstveni vestnik, vol. 72, no. 10, pp. 575 - 581.

HARTLEY, P., ADAMSON, J., CUNNINGHAM, C., EMBLETON, G. and ROMERO-ORTUNO, R., 2016. Higher Physiotherapy Frequency Is Associated with Shorter Length of Stay and Greater Functional Recovery in Hospitalized Frail Older Adults: A Retrospective Observational Study. The Journal of Frailty and Aging, vol. 5, no. 2, pp. $121-125$.

HARTLEY, P, GIBBSIN, N., SAUNDERS, A., ALEXANDER, K., CONROY, E., DIXON, R., LANG, J., LUCKETT, J., LUDDINGTON, T. and ROMERO-ORTUNO, R., 2017. The association between cognitive impairment and functional outcome in hospitalised older patients: a systematic review and meta-analysis. Age and Ageing, vol. 46, no. 4, pp. $559-567$.

HEILAND, E.F., WELMER, A.K., WANG, R., SANTONI, G., ANGLEMAN, S., FRATIGLIONI, L. and QUI, C., 2016. Association of mobility limitations with incident disability among older adults: a population-based study. Age and Ageing, vol. 45, no. 6, pp. 812 - 819 .

KOVACS, E., JONASNE, I.S., KAROCZI, C.K., KORPOS, A. and GONDOS, T., 2013. Effects of a multimodal exercise program on balance, functional mobility and fall risk in older adults with cognitive impairment: a randomized controlled single-blind study. European Journal of Physical and Rehabilitation Medicine, vol. 49, no. 5, pp. $639-648$. 
LA GROW, S., YEUNG, P, TOWERS, A., ALPASS, F. and STEPHENS, C., 2013. The impact of mobility on quality of life among older persons. Journal of Aging and Health, vol. 25, no. 5, pp. $723-736$.

LAM, F.H.M., HUANG, M.Z, LIAO, L.R., CHUNG, R.C.K., KWOK, T.C.Y.K. and PANG, M.Y.C. 2018. Physical exercise improves strength, balance, mobility, and endurance in people with cognitive impairment and dementia: a systematic review. Journal of Physiotherapy, vol. 64, no. 1, pp. $4-15$.

LIU, I.T., LEE, W.J, LIN, S.Y., CHANG, S.T., KAO, C.L. and CHENG, Y.Y., 2020. Therapeutic Effects of Exercise Training on Elderly Patients With Dementia: A Randomized Controlled Trial. Archives of Physical Medicine and Rehabilitation, vol. 101, no. 5, pp. $762-769$.

MACHIELS, M., METZELTHIN, S.F., HAMERS, J.P.H. and ZWAKHALEN, S.M.G., 2017. Interventions to improve communication between people with dementia and nursing staff during daily nursing care: A systematic review. International Journal of Nursing Studies, vol. 66, pp. $37-46$.

MAHMOOD KHAN, R., 2018. Mobility impairment in the elderly. InovAiT, vol. 11, no. 1, pp. $14-19$.

MANINI, T., 2011. Development of physical disability in older adults. Current Aging Science, vol. 4, no. 3, pp. $184-191$.

MARQUES, A. and QUEIROS, C., 2018. Frailty, Sarcopenia and Falls. In: HERTZ, K. and SANTY-TOMILSON, J., ed. Fragility Fracture Nursing: Holistic Care and Management of the Orthogeriatric Patient [online]. Cham: Springer. [viewed 15 May 2021] Available from: https://www.ncbi. nlm.nih.gov/books/NBK543821/

MEDNARODNA KLASIFIKACIJA FUNKCIONIRANJA, ZMANJŠANE ZMOŽNOSTI IN ZDRAVJA (MKF), 2006. Gibanje. In: MORAVEC BERGER, D., ed., Mednarodna klasifikacija funkcioniranja, zmanjšane zmožnosti in zdravja. Ljubljana: Inštitut za varovanje zdravja Republike Slovenije, Inštitut RS za rehabilitacijo, pp. 138 - 148.

MOGRABI, D.C., MORRIS, R.G., FICHMAN, H.C:,FARIA, C.A., SANCHEZ, M.A., RIBEIRO, P.C.C. and LOURENCO, R.A., 2017. The impact of dementia, depression and awareness on activities of daily living in a sample from a middle-income country. International Journal of Geriatric Psychiatry, vol. 33, no. 6 , pp. $807-813$.

MURMAN, D., 2015. The Impact of Age on Cognition. Seminars in Hearing, vol. 36, no. 3, pp. $111-121$.

MUSICH, S., WANG, S.S., RUIZ, J., HAWKINS, K. and WICKER, E., 2018. The impact of mobility limitations on health outcomes among older adults. Geriatric Nursing, vol. 39, no. 2, pp. $162-169$.

PEDERSEN, M.M., HOLT, N.E., GRANDE, L., KURLINSKI, L.A., BEAUCHAMP, M.K., KIELY, D.K., PETERSEN, J., LEVEILlE, S. and BEAN, J.F., 2014. Mild Cognitive Impairment Status and Mobility Performance: An Analysis From the Boston RISE Study. The journals of gerontology. 
Series A, Biological sciences and medical sciences, vol. 69, no. 12, pp. 15111518.

PERNECZKY, R., POHL, C., SORG, C., HARTMANN, J., KOMOSSA, K., ALEXOPOULOS, P., WAGENPFEIL, S. and KURZ, A., 20o6. Complex activities of daily living in mild cognitive impairment: conceptual and diagnostic issues. Age and Ageing, vol. 35, no. 3, pp. $240-245$.

SURKAN, M.J. and GIBSON, W, 2018. Interventions to Mobilize Elderly Patients and Reduce Length of Hospital Stay. Canadian Journal of Cardiology, vol. 34, no. 7, pp. $881-888$.

TERROSO, M., ROSA, N., MARQUES, A.T. and SIMOES, R., 2014. Physical consequences of falls in the elderly: a literature review from 1995 to 2010 [online]. European Review of Aging and Physical Activity, vol. 11, pp. 51 - 59. [viewed 15 May 2021] Available from: https://doi.org/10.1007/s11556O13-0134-8

UNITED NATIONS DEPARTMENT OF ECONOMIS AND SOCIAL AFFAIRS, POPULAION DIVISION, 2020. World Population Ageing 2020 Highlights: Living arrangements of older persons [online]. [viewed 19 April 2021]. Available from: https://www.un.org/development/desa/pd/ sites/www.un.org.development.desa.pd/files/undesa_pd-2020_world_ population_ageing_highlights.pdf

WORLD HEALTH ORGANISATION, 2021. Decade of Healthy Ageing 2021 - 2030 [online]. [viewed 5 May 2021]. Available from: https://www.euro. who.int/en/health-topics/Life-stages/healthy-ageing/news/news/2021/o1/ decade-of-healthy-ageing-2021-2030

WORLD HEALTH ORGANISATION, 2020. Ageing: Healthy ageing and functional ability [online]. [viewed 5 May 2021]. Available from: https:// www.who.int/westernpacific/news/q-a-detail/ageing-healthy-ageing-and-functional-ability

WU, Q., CHAN, J.S.Y. and YAN, H.J., 2015. Mild cognitive impairment affects motor control and skill learning. Reviews in the Neurosciences, vol. 27, no. 2, pp. $197-217$.

YEUNG, S.S.Y., REIJNIERSE, E.M., PHAM, V.K., TRAPPENBURG, M.C., LIM, W.K., MESKERS, C.G.M. and MAJER, A.B., 2019. Sarcopenia and its association with falls and fractures in older adults: A systematic review and meta-analysis. Journal of Cachexia, Sarcopenia and Muscle, vol. 10, no. 3, pp. $485-500$. 